\title{
A Cecal Perforation in a Blunt Trauma
}

\section{Ho Hyoung Lee, Sung Ho Han, Seok Jin Yang, Keung Han Kim, Jung suk Kim, Min Koo Lee, Oh Sang Kwon}

Department of traumatology, Jeju regional trauma center, Cheju Halla General Hospital, Jeju, Korea

Immediate cecal perforation in blunt trauma is rare. We experienced a case of perforation of the cecum after a passenger traffic accident, which is reported herein.

Key Words: Cecum; Injury; Wounds, Blunt injury; Intestinal perforation

(Trauma Image Proced 2018(1):1-2)

\section{CASE}

A 65-year-old female underwent passenger traffic accident. She was putting a seat belt. She arrived at authors` emergency department via ground ambulance from other hospital. The patient complained of generalized abdominal pain, and her initial vital signs were blood pressure 101/51 $\mathrm{mmHg}$, heart rate 85 , respiratory rate 20 , body temperature $36.8^{\circ} \mathrm{C}$ and $\mathrm{sPO} 2$ $97 \%$. A seat-belt sign was seen from her anterior chest wall to lower right abdominal wall. We detected free air and fluid collection in her abdominal cavity of computed tomography scan which was performed at the previous hospital (Fig. 3.). An emergency laparotomy was performed. About $1 \mathrm{~L}$ of fresh blood was collected in the abdominal cavity and a moderate amount of bowel spillage was detected. Multiple mesenteric lacerations were identified $190 \mathrm{~cm}$ distal area from Treitz ligament and $5 \mathrm{~cm}$ above from IC valve. Omental tearing was also identified. Cecal perforation was noted on the countermesenteric area. We decided one-stage operation. After adequate hemostasis, the omental and mesenteric tearing were repaired primarily. A partial cecaectomy was performed using stapler on the perforation of the cecum (Fig. 2.). The patient was discharged uneventfully.

\section{DISCUSSION}

In a blunt trauma, a cecal perforation is very rare. If the injury is identified without delay, cecal perforation could be managed with one-stage operation (1).

\section{Conflict of Interest Statement}

No potential conflict of interest relevant to this article was reported.

\section{REFERENCE}

1. Greer LT, Gillern SM, Vertrees AE. Evolving colon injury management: a review. The American surgeon. 2013;79(2): $119-27$.

Received: November 3, 2017 Revised: May 14, 2018 Accepted: May 14, 2018

Correspondence to: Oh Sang Kwon, Department of traumatology, Jeju regional trauma center, Cheju Halla General Hospital \# Address: 65, Doryeong-ro, Jeju-si, Jeju-do, Republic of Korea

Tel: 82-064-740-5000, Fax: 82-064-743-3110, E-mail: dr73bear@hanmail.net

Copyright (c) 2018 Korean Association for Research, Procedures and Education on Trauma. All rights reserved.

(c) This is an open-access article distributed under the terms of the Creative Commons Attribution Non-Commercial License (http://creativecommons.org/ licenses/by-nc/4.0) which permits unrestricted noncommercial use, distribution, and reproduction in any medium, provided the original work is properly cited 


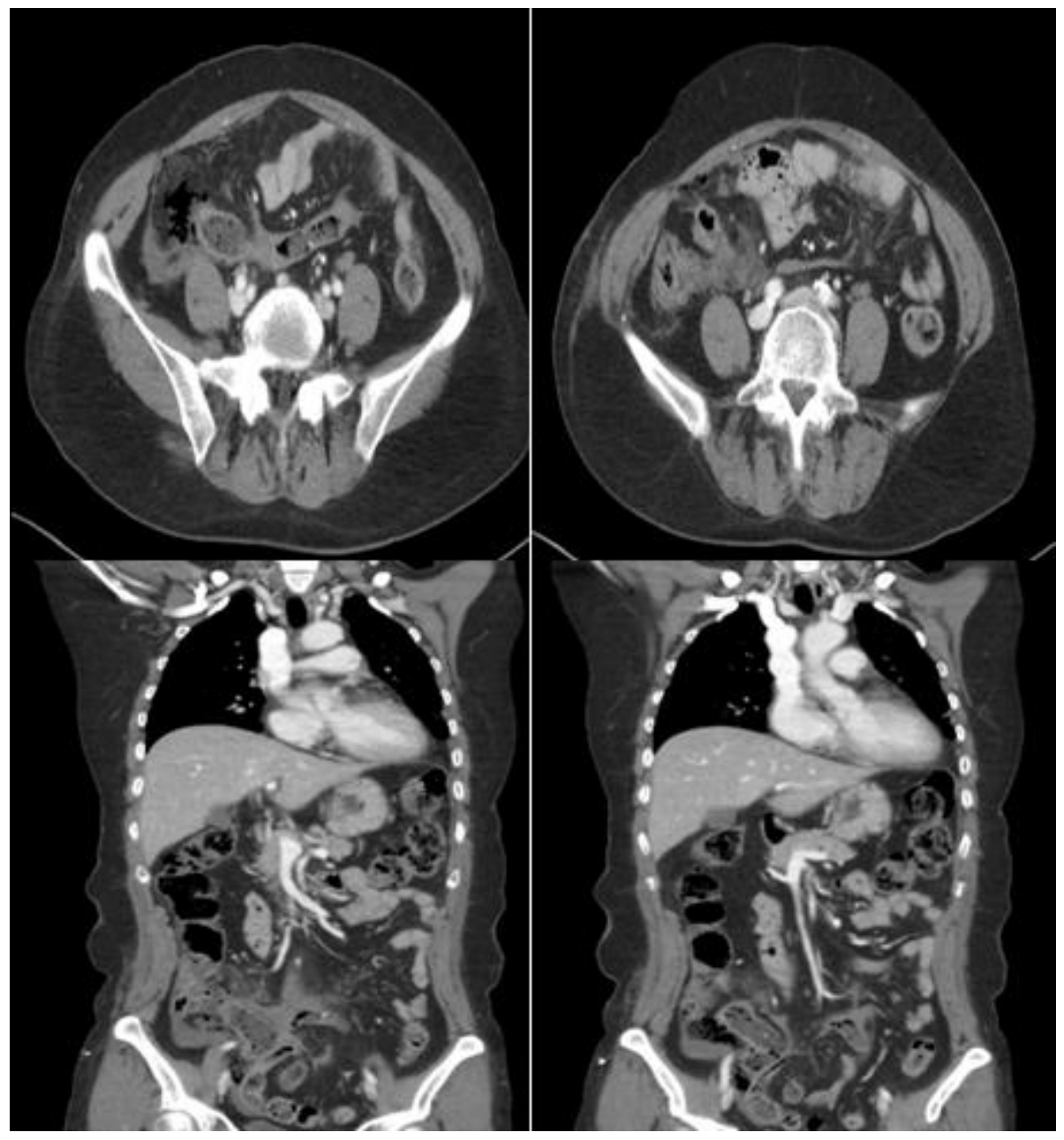

Fig. 1. The computed tomography scan shows free air and fluid collection around cecum.
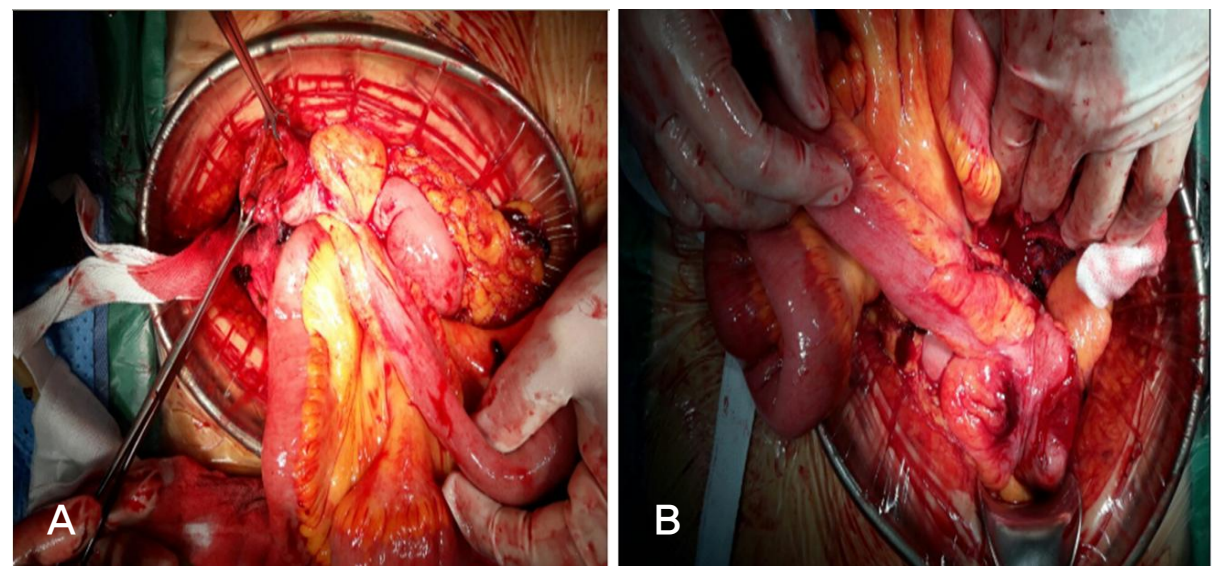

Fig. 2. (A) A free perforation was identified. (B) A partial cecectomy was performed using surgical stapler. 